\title{
Associação da Vaginose Bacteriana com 0 Parto Prematuro Espontâneo
}

\author{
Association of Bacterial Vaginosis with Spontaneous Preterm Delivery \\ Mário Henrique Burlacchini de Carvalho, Roberto Eduardo Bittar, Patrícia Ponte de Andrade e Silva Maganha \\ Sylvia Vianna Pereira, Marcelo Zugaib
}

\section{RESUM0}

Objetivo: relacionar a presença de vaginose bacteriana em gestantes com a ocorrência de parto prematuro espontâneo.

Método: foram estudadas 611 gestantes do serviço pré-natal da Clinica Obstétrica do HCFMUSP. Foram incluidas gestantes com idade gestacional confirmada por ultra-sonografia no primeiro trimestre de gestação ou duas ultra-sonografias até a $20^{a}$ semana quando havia discordância da idade gestacional no primeiro exame. Os partos prematuros eletivos foram excluidos. A pesquisa da vaginose foi realizada na $23^{a}$ ou $24^{a}$ semana de gestação por meio da técnica de coloração de Gram. O pH vaginal foi pesquisado utilizando-se fita de $p H$ Universal 0-14 produzida pela Merck. O conteúdo vaginal foi coletado com a paciente em posição ginecológica, utilizando-se espéculo não-lubrificado. O pH foi medido na parede lateral da vagina e o conteúdo para Gram foi coletado do fundo de saco vaginal utilizando-se de cotonete estéril.

Resultado: das 611 gestantes envolvidas inicialmente no estudo, foram obtidos os resultados do parto em 541. A vaginose bacteriana foi diagnosticada por bacterioscopia em 19\% dos casos. No grupo de gestantes com vaginose, 9,7\% (10/103) evoluiram com parto prematuro, contra apenas 3,2\% (14/438) no grupo negativo ( $p=0,008)$. A sensibilidade da bacterioscopia positiva para vaginose bacteriana para predição do parto prematuro foi de 41,7\%, a especificidade de $82 \%$, a acurácia de 80,2\%, com taxa de falso-positivos de $18 \%$ e risco relativo de 1,8 .

Conclusão: a vaginose bacteriana diagnosticada pelo Gram do conteúdo vaginal representa fator de risco para o parto prematuro, com risco relativo de 1,8 .

PALAVRAS-CHAVE: Vaginose bacteriana. Parto prematuro. Diagnóstico pré-natal.

\section{Introdução}

De acordo com a Organização Mundial de Saúde, o recém-nascido prematuro é aquele com menos de 37 semanas completas de gestação ${ }^{1}$. Um dos grandes problemas não solucionados da prematuridade é que a sua incidência tem se mantido estável ao longo dos anos, apesar dos esforços desenvolvidos para a sua prevenção. O parto pre-

Setor de Baixo Peso Fetal da Clínica Obstétrica do Hospital das Clínicas da Faculdade de Medicina da Universidade de São Paulo.

Correspondência:

Mário Henrique Burlacchini de Carvalho

Rua Barão do Bananal, 640/ 193, Pompéia

05024-000 - São Paulo - SP

Tel: (11) 3673-4639

e-mail: marioburlacchini@uol.com.br maturo ocorre em 6 a 10\% das gestações, dependendo das características da população estudada ${ }^{2}$. No Reino Unido, a incidência do parto prematuro está em torno de $7 \%$, desde 1953, ano em que se iniciaram os estudos mais acurados ${ }^{3}$. Nos Estados Unidos, a incidência está em torno de $10 \%$, sendo a principal causa de morbidade e mortalidade neonatal ${ }^{4,5}$. No Hospital das Clínicas da FMUSP, a incidência do parto prematuro é de $22 \%$, sendo que metade dos casos decorre do parto prematuro espontâneo ${ }^{6}$.

Atualmente a redução da prematuridade é uma das principais metas a ser alcançada na assistência pré-natal. No entanto, a dificuldade na prevenção do parto prematuro advém da multiplicidade de causas e fatores desencadeantes e da complexa fisiopatologia. 
Existem evidências de que o parto prematuro é mais freqüente entre gestantes com alteração da microflora vaginal. Porém, ainda é controverso se a infecção vaginal é realmente a causa do desencadeamento do parto prematuro ${ }^{7,8}$. A vaginose bacteriana é uma das infecções genitais mais comuns e está associada a resultados adversos da gestação, tendo sido observada também associação com o parto prematuro ${ }^{7,9,10}$. No entanto, o rastreamento sistemático das infecções vaginais no pré-natal não é universalmente aceito, uma vez que não é consenso que o seu tratamento reduz as taxas de prematuridade.

No presente estudo, procuramos correlacionar a presença de vaginose bacteriana no prénatal com o nascimento prematuro espontâneo.

\section{Pacientes e Métodos}

Este estudo foi desenvolvido de forma prospectiva e longitudinal envolvendo 611 gestantes atendidas no pré-natal geral da Clínica Obstétrica do Hospital das Clínicas da Faculdade de Medicina da Universidade de São Paulo (HCFMUSP) no período de janeiro de 1998 a março de 1999.

Os critérios de inclusão foram: gestação com feto único e vivo, na qual a datação foi realizada precocemente mediante data da última menstruação concordante com ultra-sonografia do primeiro trimestre (até 12 semanas). Quando não havia esta concordância, a idade gestacional foi calculada por meio de dois exames ultra-sonográficos compatíveis até a vigésima semana.

Foram excluidas as gestantes que tiveram parto prematuro eletivo e aquelas gestantes das quais não foram obtidas informações sobre o tipo, data do parto e evolução do recém-nascido. Foi definido como parto prematuro eletivo quando houve indicação materna ou fetal para o nascimento antes da $37^{\text {a }}$ semana.

Por ocasião da consulta, entre a $23^{a}$ e a $24^{a}$ semana, as gestantes foram informadas a respeito do estudo e se aceitassem participar, assinavam o termo de consentimento pós-informado, segundo normas da Comissão de Ética em Pesquisa do HCFMUSP.

A coleta do material para análise de vaginose bacteriana foi feita entre a $23^{a}$ e a $24^{a}$ semana. Com a gestante em posição ginecológica, realizouse exame com espéculo não-lubrificado. Primeiro era medido o $\mathrm{pH}$ vaginal no terço médio da parede lateral, utilizando-se papel indicador especial $\mathrm{pH}$ 0-14, fabricado pela Merck. Em seguida colhia-se conteúdo do fundo de saco posterior vaginal com cotonete estéril (Culturette ${ }^{\circledR}$, da Becton Dickinson Indústrias Cirúrgicas Ltda, EUA). Então o material era enviado para o Setor de Microbiologia do Laboratório Central do HCFMUSP.

A leitura do $\mathrm{pH}$ vaginal era realizada um minuto após a aplicação da fita de $\mathrm{pH}$. A técnica utilizada para a pesquisa da vaginose bacteriana foi a coloração pelo $\mathrm{Gram}^{11}$. As lâminas coletadas eram consideradas normais se houvesse predominância de Lactobacilus spp. Quando havia redução acentuada ou mesmo ausência de Lactobacillus spp. com grande crescimento de Gardnerella vaginalis, Mobiluncus sp. ou presença de célulaspista (clue cells), a paciente era considerada positiva para vaginose bacteriana. As gestantes não receberam nenhuma orientação quanto ao tratamento da vaginose bacteriana.

Os resultados da gestação foram obtidos mediante cartas-respostas pré-pagas e endereçadas à Clínica Obstétrica da FMUSP para serem respondidas após o parto, com dados sobre o mesmo. Os resultados não obtidos por este meio foram obtidos por meio de telefonemas às gestantes ou mediante busca no prontuário médico no arquivo do hospital.

Para a análise estatística, foram calculadas as freqüências absolutas e relativas das variáveis classificatórias. A análise da hipótese de igualdade de proporções entre os grupos foi efetuada utilizando-se o teste exato de Fisher. A comparação das médias dos dois grupos foi verificada fazendo uso do teste $t$ de Student. Para se avaliar a eficácia dos métodos de classificação foram utilizados os indices de sensibilidade, especificidade, taxa de falso-positivos, taxa de falso-negativos e acurácia. O nível de significância utilizado para os testes foi de $5 \%$, sendo considerados significantes os valores de $\mathrm{p}<0,05$.

\section{Resultados}

De 611 gestantes nas quais pesquisamos vaginose bacteriana o resultado do parto foi obtido em 541. A vaginose bacteriana foi diagnosticada em 103 das gestantes (19\%).

A incidência de partos prematuros foi significativamente maior no grupo de pacientes portadoras de vaginose bacteriana $(p=0,008)$. Das 103 gestantes com o exame bacterioscópico compatível com vaginose bacteriana, 10 (9,7\%) evoluíram com parto antes de 37 semanas completas, ao passo que no grupo negativo para vaginose, $14(3,2 \%)$ gestantes tiveram parto prematuro (Figura 1).

No grupo de partos prematuros, $41,7 \%$ gestantes foram positivas para vaginose bacteriana 
contra $18 \%$ das gestantes do grupo de parto a termo. Se considerarmos apenas o parto prematuro extremo (anterior a 33 semanas), a presença de vaginose bacteriana não constituiu um fator de risco $(p=0,10)$.

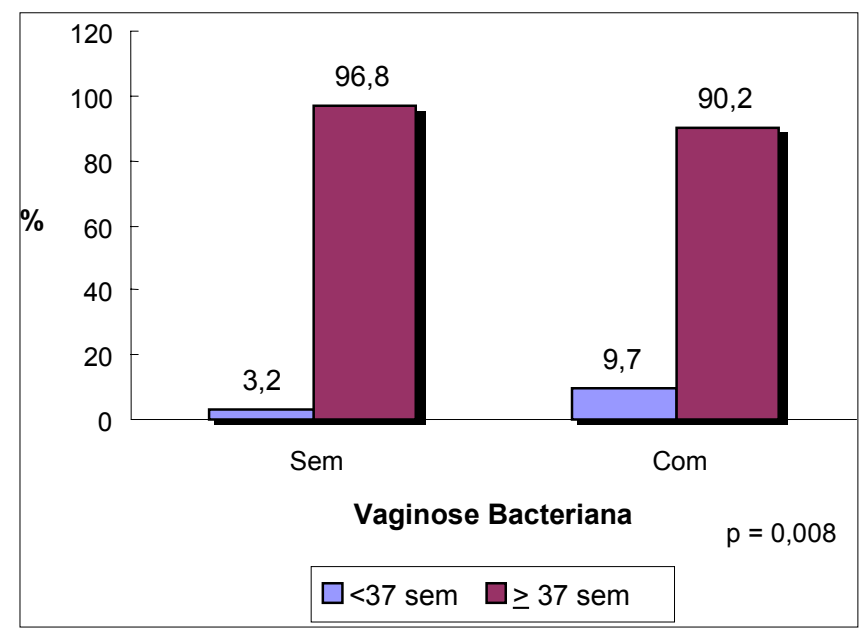

Nota: $<37$ sem: parto antes da $37^{\text {a }}$ semana; $>37$ sem: parto a termo a ou parto a termo.

Figura 1 - Porcentagem de gestantes com vaginose bacteriana em relação à idade gestacional do parto antes da $37^{\mathrm{a}}$ semana ou parto a termo.

A sensibilidade da bacterioscopia positiva para vaginose bacteriana quanto a predição do parto prematuro foi de $41,7 \%$, a especificidade de $82 \%$, a acurácia de $80,2 \%$, com taxa de falso-positivos de $18 \%$ e risco relativo de 1,8 .

Não houve associação significativa entre a presença de vaginose bacteriana e as características sociodemográficas das gestantes, como por exemplo cor da pele e escolaridade.

A mediana do $\mathrm{pH}$ vaginal, no grupo de gestantes com vaginose bacteriana, foi de 4,8 , e no grupo sem vaginose, de 4,3 ( $\mathrm{p}=0,0001)$. A sensibilidade do $\mathrm{pH}$ vaginal maior que 4,5 foi de $77,3 \%$ e o valor preditivo positivo de $39,5 \%$, para um falsopositivo de $25,9 \%$, na identificação de gestantes com vaginose bacteriana.

A mediana do $\mathrm{pH}$ vaginal no grupo de gestantes com parto a termo foi de 4,4 e no grupo de parto prematuros foi de 4,6 , o que não representa diferença estatisticamente significativa $(p=0,20)$. Utilizando o ponto de corte do $\mathrm{pH}$ vaginal $<4,5$ e $>4,5$, não houve diferença significativa na incidência de partos prematuros entre os dois grupos estudados $(p=0,135)$.

\section{Discussão}

Visando uma adequada prevenção do trabalho de parto prematuro é importante identificar seus fatores de risco durante o pré-natal.

A composição anormal da flora vaginal é um dos principais fatores de infecção intra-amniótica, o que pode desencadear o parto prematuro ${ }^{7,8}$. Em mais de $75 \%$ dos casos com cultura positiva de líquido amniótico, os mesmos microrganismos foram encontrados nos exames vaginais e endocervicais ${ }^{12}$. No entanto, o conceito de flora vaginal normal e anormal não é de fácil definição. A flora vaginal é um ecossistema dinâmico e complexo, que pode contar com a presença de qualquer bactéria por um período curto de tempo, sem necessariamente significar um achado patológico ${ }^{13}$.

A vaginose bacteriana é uma condição polimicrobiana em que a flora de Lactobacillus spp. normal é substituída por um grande número de outros microorganismos, principalmente anaeróbios, como Gardnerella vaginalis, Prevotella sp., Bacterioides sp., Mobiluncus sp., Peptostreptococcus spp. e Mycoplasma hominis, que são alguns dos germes freqüentemente associados à vaginose bacteriana. O estímulo desencandeante desta transformação não está bem estabelecido ${ }^{14}$.

A vaginose bacteriana neste estudo foi pesquisada pelo método da coloração de Gram. Este foi o método escolhido em virtude de ser descrito na literatura como o melhor teste diagnóstico para vaginose bacteriana, além de ser de fácil realização e de baixo custo ${ }^{15}$. Utilizamos também o $\mathrm{pH}$ vaginal para o diagnóstico da vaginose, e observamos que, no grupo de gestantes com infecção, o $\mathrm{pH}$ vaginal foi significativamente mais elevado que no grupo de gestantes com microflora vaginal normal. No entanto, a medida do $\mathrm{pH}$ não se correlacionou com a idade gestacional do parto. Desta forma, o $\mathrm{pH}$ vaginal pode ser um método barato e de fácil realização para investigação de vaginose bacteriana, porém, não parece útil na predição do trabalho de parto prematuro.

Verificamos que $19 \%$ das gestantes tiveram resultado de Gram compatível com vaginose bacteriana. Esta taxa é semelhante à observada em outro estudo realizado no mesmo serviço ${ }^{16}$. No entanto, neste estudo os autores avaliaram gestantes que apresentavam corrimento vaginal durante o pré-natal, sendo sua população sintomática para infecções vaginais, de tal forma que a prevalência de infecção vaginal foi de $72,2 \%$ e a de vaginose bacteriana de $19,2 \%$, que é semelhante a por nós encontrada.

Optamos pelo não-tratamento rotineiro das gestantes portadoras de vaginose bacteriana, como forma de avaliar se a presença desta infecção representaria risco real para o parto prematuro. Esta conduta pode ser embasada nos estudos que demonstraram que o tratamento da vaginose bacteriana na gestação, mesmo quan- 
do se obtém sucesso terapêutico, não necessariamente leva a uma redução na incidência de partos prematuros ${ }^{17-19}$.

A vaginose bacteriana revelou-se um fator de risco para a prematuridade em nosso estudo. Das 103 gestantes positivas para vaginose bacteriana, 9,7\% evoluíram para parto prematuro. Já no grupo de gestantes negativas para esta infecção, apenas 3,2\% evoluíram para parto com menos de 37 semanas. A presença de vaginose bacteriana na bacterioscopia do conteúdo vaginal levou a um risco relativo de 1,8 para parto prematuro comparado ao risco das gestantes com bacterioscopia do conteúdo vaginal normal.

Outro estudo encontrou incidência de partos prematuros de $12,3 \%$, entre as gestantes com vaginose bacteriana, quando examinadas entre a $22^{\mathrm{a}}$ e a $24^{\mathrm{a}}$ semana de gestação, com risco relativo de $1,3^{20}$. Esta taxa de partos prematuros é bem semelhante à encontrada em nosso estudo, considerando o parto antes da $37^{\text {a }}$ semana. Quando considerado o parto prematuro antes da $33^{\mathrm{a}}$ semana, a incidência de partos prematuros, no grupo de gestantes com vaginose bacteriana, foi de $3,2 \%$, assemelhando-se à taxa de 3,8\% encontrada em nosso estudo. No entanto, estes autores observaram associação estatisticamente significativa entre a vaginose bacteriana e o parto prematuro para parto com menos de 33 semanas, o que não ocorreu no presente estudo.

Gestantes que apresentavam teste de Gram compativel com vaginose bacteriana na $24^{a}$ semana apresentaram risco aumentado para o parto prematuro, com risco relativo de $2,8^{21}$. Outro estudo observou que $5,5 \%$ das gestantes com vaginose bacteriana, na $24^{\mathrm{a}}$ semana de gestação, evoluíram com parto prematuro, sendo a sensibilidade do teste positivo para vaginose de $29,4 \%$ na identificação de gestantes com parto prematuro ${ }^{22}$. Estes números são pouco mais baixos que as taxas encontradas no nosso estudo. Contudo, os autores consideraram partos prematuros apenas aqueles ocorridos antes da $35^{\mathrm{a}}$ semana. Nesta pesquisa, não foi observada associação estatisticamente significativa entre a presença de infecção pela vaginose bacteriana e o parto antes da $35^{\mathrm{a}}$ semana, o que também foi verdadeiro em nosso estudo, quando considerado o parto antes da $33^{a}$ semana.

A associação da vaginose bacteriana com o parto prematuro pode ser reforçada pela evidência de que 30 a $40 \%$ dos partos prematuros apresentam alguma evidência de infecção subclínica intra-uterina ${ }^{23}$. Os microorganismos associados à vaginose bacteriana estimulam a produção de fosfolipases A2 e C, que levam à sintese de prostaglandinas. As prostaglandinas podem então induzir a contratilidade miometrial e alterações na matriz extracelular do colo uterino, levando ao esvaecimento e dilatação do colo. Colagenases, mucinases e siladases também produzidas pelos germes presentes na vaginose bacteriana atuariam sinergicamente com as prostaglandinas na dilatação do colo uterino e desta forma aumentando o risco de desencadeamento de parto prematuro $^{24}$.

Outros autores, no entanto, não encontraram associação entre a presença de vaginose bacteriana entre a $20^{\mathrm{a}}$ e a $24^{\mathrm{a}}$ semana e o parto prematuro. Note-se que foram avaliadas apenas 140 gestantes assintomáticas ${ }^{25}$.

Este estudo demonstrou que a vaginose bacteriana apesar de elevar o risco para o parto prematuro, apresentou no entanto baixa sensibilidade $(42,8 \%)$ e baixo valor preditivo positivo $(9,7 \%)$ para o parto prematuro; a prematuridade foi aproximadamente três vezes mais comum nas gestantes com vaginose bacteriana do que nas gestantes com flora vaginal normal. Desta forma, quando diante de uma gestante com diagnóstico de vaginose bacteriana sugerimos que o tratamento seja realizado assim como preconizamos que em gestantes com antecedente de partos prematuros seja feita pesquisa de vaginose bacteriana e, se positiva, esta deve ser tratada.

\section{SUMMARY}

Purpose: to evaluate the relationship between bacterial vaginosis $(B V)$ and spontaneous preterm delivery.

Method: a total of 611 pregnant women from the general antenatal clinic of the "Clínica Obstétrica do Hospital das Clínicas da Universidade de São Paulo" were enrolled in this study. All pregnancies were dated by an early scan. Iatrogenic preterm deliveries were excluded. The presence of bacterial vaginosis was evaluated between 23 and 24 weeks of pregnancy by a Gram stain of the vaginal smear collected from the posterior vaginal wall using a sterile swab. Vaginal pH was also assessed from the lateral vaginal wall by a Universal 0-14 pH strip produced by Merck.

Result: a complete follow-up was obtained in 551 patients and bacterial vaginosis was diagnosed in 103 (19\%) cases. Among the patients with $B V$ in the vaginal smear, 9.7\% delivered before 37 weeks against only $3.2 \%$ in the group with normal vaginal smear $(p=0.008)$. The sensitivity, specificity, accuracy and false-positive rate for preterm delivery in the presence of bacterial vaginosis on Gram stain of the vaginal smear were 41.7, 82, 80.2 and $18 \%$, respectively, with a relative risk of 1.8 for preterm delivery. The mean vaginal $p H$ in the group of positive $B V$ was 4.9 and in the group with normal smear it was $4.3(p=0.0001)$.

Conclusion: bacterial vaginosis during pregnancy increases 
the risk for spontaneous preterm delivery, with a relative risk of 1.8 .

KEY WORDS: Bacterial vaginosis. Preterm delivery. Prenatal diagnosis.

\section{Referências}

1. Cunningham FG, Gant NF, Leveno KJ, Gilstrap LC, Hauth JC, Wenstrom KD. William Obstetrics. $21^{\text {st }}$ ed. New York: McGraw-Hill; 2001. p.689.

2. Morrison JJ, Rennie JM. Clinical, scientific and ethical aspects of fetal and neonatal care at extremely preterm periods of gestation. $\mathrm{Br} \mathrm{J}$ Obstet Gynaecol 1997; 104:1341-50.

3. Carroll SG, Sebire NJ, Nicolaides KH. Preterm Prelabour Amniorrehxis. In: Carroll SG, Sebire NJ, Nicolaides KH. Preterm delivery: incidence and complications, causes and prevention. 1st ed. London: Parthenon; 1996. p. 1-50.

4. Guyer B, Martin JA, MacDorman MF, Anderson RN, Strobino DM. Annual summary of vital statistics1996. Pediatrics 1997; 100:905-18.

5. Lockwood C, Kuczynski E. Markers of preterm delivery risk. Ultrasound Obstet Gynecol 1998;12:301-3.

6. Perroni AG, Bittar RE, Fonseca ESB, Messina ML, Marra KC, Zugaib M. Prematuridade eletiva: aspectos obstétricos e perinatais. Rev Bras Ginecol Obstet 1999; 10:67-71.

7. McDonald HM, O'Loughlin JA, Jolley P, Vigneswaran $\mathrm{R}, \mathrm{McDonald}$ PJ. Vaginal infection and preterm labour. Br J Obstet Gynaecol 1991; 98:427-35.

8. Goldenberg RL, Andrews WW, Yuan AC, MacKay HT, St. Louis ME. Sexually transmitted diseases and adverse outcomes of pregnancy. Clin Perinatol $1997 ; 24: 23-41$

9. Hay PE, Lamont RF, Taylor-Robinson D, Morgan DJ, Ison C, Pearson J. Abnormal bacterial colonization of the genital tract and subsequent preterm delivery and late miscarriage. BMJ 1994; 308:295-8.

10.Hillier SL, Nugent RP, Eschenbach DA, et al. Association between bacterial vaginosis and preterm delivery of a low-birth-weight infant. $\mathrm{N}$ Engl J Med 1995; 333:1737-42.

11.Isenberg HD. Essential procedures for clinical microbiology. Washington, D.C:ASM Press; 1998. p.39-50.

12.Main DM. The epidemiology of preterm birth. Clin Obstet Gynecol 1988; 31:521-32.
13. Hill GB, Eschenbach DA, Holmes KK. Bacteriology of the vagina. Scand J Urol Nephrol 1985; Suppl 86:23-39.

14.Holst E, Wathne B, Hovelius B, Mardh PA. Bacterial vaginosis: microbiological and clinical findings. Eur J Clin Microbiol 1987; 6:536-41.

15.Hillier SL, Krohn MA, Rabe LK, Klebanoff SJ, Eschenbach DA. The normal vaginal flora $\mathrm{H} 2 \mathrm{O} 2-$ producing lactobacilli and bacterial vaginosis in pregnant women. Clin Infect Dis 1993; 16 Suppl 4:S273-81.

16.Longo e Pereira LC. Infecções cervicovaginais na gestação: prevalência dos agentes etiológicos, fatores de risco e associação com bacteriúria assintomática [dissertação]. São Paulo: Universidade de São Paulo; 1997.

17.McGregor JA, French JI, Jones W, et al. Bacterial vaginosis is associated with prematurity and vaginal fluid mucinase and sialidase: results of a controlled trial of topical clindamycin cream. Am J Obstet Gynecol 1994; 170:1048-60.

18. Hauth JC, Goldenberg RL, Andrews WW, DuBard MB, Copper RL. Reduced incidence of preterm delivery with metronidazole and erythromycin in women with bacterial vaginosis. N Engl J Med 1995; 333:1732-6.

19.Joesoef MR, Hillier SL, Wiknjosastro G, et al. Intravaginal clindamycin treatment for bacterial vaginosis: effects on preterm delivery and low birth weight. Am J Obstet Gynecol 1995; 173:1527-31

20.Goldenberg RL, Iams JD, Mercer BM, et al. The preterm prediction study: the value of new $v$ s standard risk factors in predicting early and all spontaneous preterm births. Am J Public Health 1998; 88:233-8.

21.Hay PE, Lamont RF, Taylor-Robinson D, Morgan DJ, Ison C, Pearson J. Abnormal bacterial colonisation of the genital tract and subsequent preterm delivery and late miscarriage. BMJ 1994; 308:295-8.

22.Meis PJ, Goldenberg RL, Mercer B, et al. The preterm prediction study: significance of vaginal infections. Am J Obstet Gynecol 1995; 173:1231-5.

23.Ugwumadu AH. Cervical morphology in pregnancy, bacterial vaginosis and the risk of preterm delivery. Ultrasound Obstet Gynecol 2000; 15:174-6.

24. Gomez R, Ghezzi F, Romero R, Munhoz H, Tolosa JE, Rojas I. Premature labor and intra-amniotic infection. Clinical aspects and role of the cytokines in diagnosis and pathophysiology. Clin Perinatol 1995; 22:281-342.

25.Crane JM, Armson BA, Dodds L, Feinberg RF, Kennedy W, Kirkland SA. Risk scoring, fetal fibronectin, and bacterial vaginosis to predict preterm delivery. Obstet Gynecol 1999; 93:517-22. 